at enrolment in BiKeR. More patients with a history of uveitis treated with ADA were included in BiKeR initiating ADA ( $n=98$ of $238,41.2 \%$ ). Patients with uveitis had a lower age at JIA onset in comparison to patients without uveitis (mean 3.6 (SD 3.0) versus 7.0 (SD 4.5) years). A total of 142 recurrent ( $84 \%$ of 169 ) uveitis events were reported in 93 patients and for 27 patients $(1.3 \%$ of 2,041$)$ was an incident uveitis reported during follow-up. More than one uveitis event was reported for 32 patients with a maximum number of 4 uveitis flares in 3 patients. Nineteen uveitis flares $(11.2 \%$ of 169$)$ were reported for patients after the age of 18 . The longer the time since DMARD discontinuation the fewer uveitis events occurred. Uveitis events were significantly more often reported in the first 24 months after MTX discontinuation (<6 months: OR=3.19, $95 \% \mathrm{Cl}: 1.70$ to 5.96 ; 6 to $<12$ months: $\mathrm{OR}=2.06,95 \% \mathrm{Cl}: 1.01$ to $4.66 ; 12$ to $<24$ months: $\mathrm{OR}=2.20$, $95 \% \mathrm{Cl}: 1.14$ to 4.25 ) and in the first three months after biological DMARD discontinuation (OR=5.4, 95\%Cl: 1.56 to 18.33). Patients with a MTX dose of $\leq 10 \mathrm{mg} /$ $\mathrm{m}^{2}$ at last MTX intake had a higher likelihood for uveitis events $(\mathrm{OR}=1.40,95 \% \mathrm{Cl}$ : 1.02 to 1.92$)$.

Conclusion: This is the first study that analyzed the risk of uveitis after DMARD withdrawal. Uveitis relapses are common. Patients who discontinued DMARD therapy were at high risk for uveitis within the first 3 to 24 months after discontinuation. Rheumatologists and ophthalmologists should be aware about this risk which should lead to a regular uveitis screening after DMARD withdrawal.

Disclosure of Interests: Jens Klotsche: None declared, Ariane Klein: None declared, Martina Niewerth: None declared, Tilmann Kallinich: None declared, Daniel Windschall: None declared, Johannes-Peter Haas: None declared, Frank Weller-Heinemann Speakers bureau: Pfizer, Abbvie, SOBI, Roche, Novartis, Ton Hospach: None declared, Frank Dressler: None declared, Kirsten Minden: None declared, Gerd Horneff: None declared

DOI: 10.1136/annrheumdis-2021-eular.4014

\section{OP0166 \\ DISEASE ACTIVITY IN CHILDREN WITH JUVENILE IDIOPATHIC ARTHRITIS AFTER SIMULTANEOUS PCV13 AND HIB VACCINATION: A COHORT STUDY}

O. Lomakina ${ }^{1}$, E. Alexeeva ${ }^{1,2}$, T. Dvoryakovskaya $^{1}, \mathrm{~K}$. Isaeva ${ }^{1}$

A. Chomakhidze ${ }^{1}$, R. Denisova ${ }^{1}$, A. Mamutova ${ }^{1}$, A. Fetisova ${ }^{1}$, M. Gautier ${ }^{1}$ K. Chibisova ${ }^{1}$, D. Vankova ${ }^{1}$, E. Krekhova ${ }^{1,2}$, M. Shingarova ${ }^{2}$, I. Kriulin ${ }^{1,2}$ I. Tsulukiya ${ }^{1}$, I. Zybkova ${ }^{1}$, N. Tkachenko ${ }^{1}$. 'National Medical Research Center of Children's Health, Department of Rheumatology, Moscow, Russian Federation; ${ }^{2}$ Sechenov First Moscow State Medical University (Sechenov University), Pediatrics and pediatric rheumatology, Moscow, Russian Federation

Background: The safety of vaccination of children with rheumatic diseases is determined not only by the risk of adverse events but also by the risk of exacerbation of the disease. The simultaneous administration of several vaccines can increase the likelihood of these events.

Objectives: To evaluate the clinical and laboratory signs of disease activity in children with juvenile idiopathic arthritis (JIA) after simultaneous vaccination against pneumococcal and Haemophilus influenzae type b (Hib) infections.

Methods: We included hospitalized patients with JIA ages 2 through 18 without serious comorbidity, immunized with polysaccharide conjugate vaccines against pneumococcal (PCV13) and Hib infections. Vaccines were administered $(0.5 \mathrm{ml}$ each) concurrently subcutaneously into the deltoid area. In all children before and 3 weeks after vaccination, clinical (joints with active arthritis, uveitis activity) and laboratory signs (increased ESR, concentrations of highly sensitive C-reactive protein - hsCRP, and calprotectin) of JIA activity were assessed. Serum hsCRP and calprotectin were quantified by ELISA. The upper limit of the reference interval for hsCRP was considered (according to the manufacturer's instructions) a value of $8.2 \mathrm{mg} / \mathrm{L}$, for calprotectin $-2.9 \mu \mathrm{g} / \mathrm{ml}$, and for ESR $->10 \mathrm{~mm} / \mathrm{h}$.

Results: The study included 430 patients with JIA (girls $60.9 \%$ ), median (IQR) age -11.1 years (7.3 to 14.4 ), onset of JIA -4.7 years (2.4 to 8.6). Patients with persistent oligoarticular JIA numbered 149 (34.7\%), polyarticular RF-negative - 148 (34.4\%), systemic - 101 (23.4\%), enthesitis-related - 20 (4.7\%), and polyarticular RF-positive JIA - 12 (2.8\%). Biologic disease-modifying antirheumatic drugs (DMARDs) were administered to 278 (64.7\%), non-biologic DMARDs (mostly methotrexate) $-282(65.6 \%)$, corticosteroids $-45(10.5 \%)$, and NSAIDs - $18(4.2 \%)$ patients. Three weeks after vaccination, out of $100(23.3 \%)$ patients with initially active joints, signs of active arthritis remained in 96 patients, of which 16 patients had a decrease in the median (IQR) number of active joints by 4 ( 2 to 8). Among patients without active joints at baseline, signs of active arthritis were not subsequently detected. Before vaccination, 9 patients had uveitis in the exacerbation phase, 7 - in the subactive phase, and 41 - in the remission phase. After vaccination, exacerbation of uveitis persisted in 4 patients. There were no new cases of uveitis or its exacerbation. The dynamics of laboratory signs of JIA activity are presented in Table 1. Initially, the high concentration of calprotectin was found in 191 (44.4\%) patients, and after vaccination - in 220 (51.2\%) patients; the difference was $6.7 \%(95 \% \mathrm{Cl} 1.0-12.5)$; hsCRP - in $34(7.9 \%)$ and $51(11.9 \%)$ patients; the difference was $4.0 \%(95 \% \mathrm{Cl} 0.6$ - 7.3$)$; high ESR - in $76(17.7 \%)$ and
$41(9.5 \%)$ patients; the difference was $-8.1 \%(95 \% \mathrm{Cl}-11.6$ to -4.7$)$, respectively. An independent predictor of new cases of high concentration of hsCRP $(n=36)$, but not new cases of high concentration of calprotectin $(n=94)$, was the initial number of joints with active arthritis - odds ratio 2.37 (95\% Cl $1.14-4.93)$.

Table 1. Laboratory signs of JIA activity after simultaneous administration of vaccines against pneumococcal (PCV13) and Hib-infections

\begin{tabular}{|c|c|c|c|c|}
\hline \multirow[b]{2}{*}{ Variables } & Baseline & After 3 weeks & \multirow[b]{2}{*}{ Ratio* } & \multirow[b]{2}{*}{$\mathbf{p}^{\star *}$} \\
\hline & \multicolumn{2}{|c|}{ Geometric mean $(95 \% \mathrm{Cl})$} & & \\
\hline Calprotectin, $\mu \mathrm{g} / \mathrm{ml}$ & $2.93(2.70-3.17)$ & $3.15(2.92-3.40)$ & $1.08(0.99-1.17)$ & 0.087 \\
\hline hsCRP, mg/L & $0.69(0.60-0.78)$ & $0.79(0.69-0.90)$ & $1.15(0.99-1.33)$ & 0.073 \\
\hline $\mathrm{ESR}, \mathrm{mm} / \mathrm{h}$ & $4.4(4.0-4.8)$ & $3.7(3.4-4.0)$ & $0.84(0.78-0.90)$ & 0.001 \\
\hline
\end{tabular}

Note. $\mathrm{Cl}$ - confidence interval. * Ratios of paired observations $(95 \% \mathrm{Cl}) .{ }^{* *} \mathrm{P}$-value calculated in paired samples t-test.

Conclusion: Simultaneous vaccination against pneumococcal (PCV13) and Hib-infections in children with JIA produced no negative dynamics of the traditional indicators of disease activity (joint activity, uveitis, high ESR). At the same time, 3 weeks after vaccination, an increase in the concentration of calprotectin and hsCRP was found in a small number of patients $(<10 \%)$.

Disclosure of Interests: None declared

DOI: 10.1136/annrheumdis-2021-eular.3457

\begin{tabular}{|l|l}
\hline OP0167 & THE ROLE OF LUNG ULTRASOUND IN THE \\
DIAGNOSIS OF INTERSTITIAL LUNG DISEASE IN \\
CHILDREN WITH DERMATOMYOSISTIS
\end{tabular}

R. Dertkgil ${ }^{1}$, C. Cappello ${ }^{1}$, S. Dertkigil ${ }^{1}$, R. Marini ${ }^{2}$, S. Appenzeller ${ }^{3} .{ }^{1}$ UNICAMP, Radiology, Campinas, Brazil; ${ }^{2}$ UNICAMP, Pediatrics, Campinas, Brazil;

${ }^{3}$ UNICAMP, Orthopedics, Rheumatology and Traumatology, Campinas, Brazil

Background: Dermatomyositis is a multi organ autoimmune disease wich is commonly complicated with interstitial lung disease. Chest high-resolution computed tomography (HRCT) is still considered the diagnostic gold standard for interstitial lung disease and is quantification, however he increasing use of lung ultrasound may play an important role in the future.

Objectives: The aim of our study was to determine the diagnostic value of lung ultrasound in the detection and progression of interstitial pulmonary disease in patients with dermatomyositis.

Methods: Twenty two subjects with dermatomyositis diagnosed according to the American College of Rheumatology criteria were enrolled ( 6 males, 16 females; mean age: $15,8 \pm 8.8$ years; range: 6 to 29 years). All subjects underwent high resolution computed tomography followed by transthoracic ultrasound for comet tail sign detection and pleural irregularity in order to predict the degree of interstitial lung disease. The modified transthoracic ultrasound assessment was performed at 06 thoracic regions each side. The Warrick score was calculated according standard high-resolution chest computed tomography images that were evaluated independently from each other by two thoracics radiologists

Results: A significantly positive correlation between transthoracic ultrasound and the severity of pulmonary involvement, as seen by the number of B lines (Spearman 's correlation coefficient $=0.80, p<0.001$ ), and the number of positive areas (regions wih more than $3 \mathrm{~B}$ lines) (Spearman 's correlation coefficient $=0.75$, $\mathrm{p}<0.001$ ) were found. When compared with high-resolution chest computed tomography as the gold standard method, the sensitivity, specificity, of transthoracic ultrasound was $96.4 \%, 83,3 \%$ respectively. Addicionally the number of $\mathrm{B}$ lines (sum of 35 or more $B$ lines) and a number of B lines positive areas ( 7 or more regions with at least $3 \mathrm{~B}$ lines) cut of allowed to discriminate the inflamatory pattern (ground glass) to those with structural pattern (honeycomb and pulmonary cysts)

Conclusion: Our study showed that transthoracic ultrasound comet tails scoring system could be useful in the assessment of the pulmonary involvement in patients with dermatomyositis, and should be considered as a primary screening exam to exclude lung involvement, rather than routine chest CT scans in assimptomatic patients.

Disclosure of Interests: None declared

DOI: 10.1136/annrheumdis-2021-eular.4033

\section{OP0168 IN DEFICIENCY OF ADENOSINE DEAMINASE 2}

U. Kaya Akca ${ }^{1}$, E. Sag2, Ş. Ünal ${ }^{3}$, M. Kasap-Cuceoglu2, Y. Bilginer2, S. Özen2. ${ }^{1}$ Hacettepe University School of Medicine, Pediatric Rheumatology, Ankara, Turkey; ${ }^{1}$ Hacettepe University School of Medicine, Pediatric Rheumatology, Ankara, Turkey; ${ }^{3}$ Hacettepe University School of Medicine, Pediatric Hematology, Ankara, Turkey 